\title{
MEDIACIÓN FAMILIAR INTRAPROCESAL: RESPUESTA A LOS INTERROGANTES PLANTEADOS TRAS LA REFORMA DE LOS PROCESOS MATRIMONIALES DE 2005
}

\author{
Pilar LASHERAS HERRERO \\ PROFESORA DE DERECHO PROCESAL \\ UNIVERSIDAD DE LA RIOJA
}

s u m a r i o

I. Introducción. 2. Hacia la mediación en los procesos matrimoniales. 2.I. Especialización y primeras experiencias judiciales. 2.2. La mediación familiar en la ley $15 / 2005$, de 8 de julio. 3. Ubicación procesal del procedimiento de mediación. 3.I Momentos de inicio del procedimiento de mediación. 3.2. Ámbito procedimental de la mediación. 4. Decisión de acudir a la mediación. 4.I. Iniciativa de las partes. 4.2. Decisión judicial. 5. Mediación pública y/o mediación privada. 6. La figura del mediador. 6.I. Función del mediador familiar. 6.2. Conocimientos legales y formación del mediador. 6.3. Mediador individual y entidades de mediación. 6.4. Código deontológico. 7. Conclusión.

\section{Introducción}

A pesar del poco tiempo transcurrido desde la reforma que introdujo la separación y el divorcio en España, los problemas que se plantean en la mayoría de los procesos matrimoniales constituyen una preocupación constante de nuestra sociedad. El considerable aumento de la litigiosidad y la experiencia diaria de los juzgados y tribunales demuestran que se trata de conflictos que no terminan de resolverse con la sentencia judicial.

Esta parte del ordenamiento a la que nos referimos, el Derecho de Familia, participa de unos caracteres propios que lo diferencian de otros ámbitos, y que hacen que se haya considerado una rama intermedia entre el Derecho Privado y el Derecho Público.

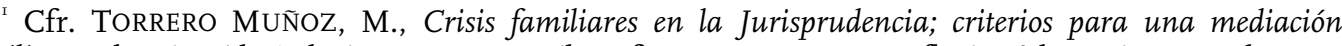
familiar, Valencia: Ed. Sedavi, I999, p. 2I. El profesor DIEZ-PICAZO reflexionó hace tiempo sobre esa cuestión al analizar la presencia de la autonomía privada en este campo. Sobre el particular, vid. 
Ciertamente las normas que rigen esta materia son en gran medida de ius cogens y los procesos matrimoniales, al estar implicado el interés público inherente a su objeto procesal $^{2}$, responden a principios distintos a los generales del proceso civil $l^{3}$. La acción para resolver el vínculo matrimonial es imperativamente jurisdiccional, y es por ello que parece lógico que sea desde el ámbito del Derecho Procesal desde el que se estudien las diferentes soluciones que el legislador adopta para paliar los problemas que se crean tras los procesos familiares. Además, no olvidemos que las relaciones familiares, al necesitar el refrendo judicial, pierden una parte de su privacidad, y que en ellas también coexisten intereses que el ordenamiento jurídico debe proteger, como son el de los menores o los discapacitados.

Sin embargo, ello no impide que en este tipo de pleitos pueda reconocerse un cierto margen a la autonomía de la voluntad, siempre y cuando los acuerdos de las partes en conflicto se refieran a materias disponibles, previstas en la legislación civil ${ }^{4}$.

La reforma de la LEC y del Código Civil que llevó a cabo la Ley I5/2005, de 8 de julio, introduciendo por primera vez en una legislación procesal el instituto de la mediación familiar, apunta a esa búsqueda de nuevas soluciones a los tradicionales problemas familiares. El legislador exhorta a nuestros jueces a propiciar el acuerdo entre los cónyuges respecto de las medidas a adoptar, señalando, expresamente, que la intervención judicial debe reservarse para cuando haya sido imposible el pacto entre ellos. Esto supone la inclusión de la mediación como instrumento a utilizar en el seno de la regulación de los procedimientos matrimoniales, y el reconocimiento a su vez de que el modelo jurisdiccional utilizado tradicionalmente para la resolución de controversias ha demostrado no ser el medio más acertado para mitigar o aliviar los conflictos familiares.

En efecto, es un hecho que el tradicional uso de la vía contenciosa tiende a mantener y reproducir el esquema ganador-perdedor, favoreciendo con ello la confrontación y la imposición de una decisión a las partes, aunque sea por el órgano jurisdiccional..$^{5}$ Además, como se ha llegado a afirmar, ganar en un proceso judicial contradictorio no significa resolver el conflicto $^{6}$, cosa que se hace patente con la mera observancia de las extensas y conflictivas ejecuciones de las sentencias dictadas en los procesos familiares. Es una realidad indiscutida que, a pesar de una resolución judicial con forma de sentencia o de auto, existen parejas que tras el proceso declarativo siguen manteniendo una confrontación continua y exacerbada que no llegan a superar. En el ámbito familiar la experiencia ha demostrado que conseguir un acuerdo sólido y satisfactorio para ambos cónyuges resulta fundamental, especialmente de cara al cumplimiento de lo pactado 7 . Ello ha motivado la búsqueda de un ambiente pacificador, adecuado para que las negociaciones se produzcan sin enfrentamientos, y en el cual los

ORTUÑo MuÑoz, P., «La aprobación de los acuerdos en mediación familiar», en Apuntes de Psicología I8 (2-3), Sevilla, 2000, p. 290.

${ }^{2}$ Como dispone en su apartado XIX la Exposición de Motivos de la LEC, en atención a la importancia de la relación matrimonial como célula de la familia, y la especial protección que le deparan los poderes públicos. Vid. Gimeno Sendra, V., Derecho Procesal Civil. II. Procesos especiales, Madrid: Edit. Colex, 2005, p. 289.

${ }^{3}$ Cfr. Ortells Ramos, M., Derecho Procesal Civil, Pamplona: Ed. Aranzadi, 4 a ed, 2003, p. iı68.

${ }^{4}$ Cfr. Cucarella Galiana, L. A., «Consideraciones procesales en torno a la mediación familiar», Anuario de Justicia alternativa 4, 2003, p. 233.

${ }^{5}$ En tal sentido, ROMERO NAVARRO, F., «La mediación familiar. Un ejemplo de aplicación práctica: la comunicación a los hijos de la separación a los padres. El papel del mediador», Revista del $M^{\circ}$ de Trabajo y Asuntos Sociales 40, Madrid, 2002, p. 37.

${ }^{6}$ Así, MEjÍA, J. F., «La mediación judicial», en Congreso Internacional de Mediación Familiar, Valladolid, 3I de Mayo y I de Junio de 2004, p. I26.

${ }^{7}$ Cfr. MEJÍA, J. F., «La mediación judicial», cit., p. I26. 
miembros de la pareja asuman el papel de verdaderos protagonistas en la resolución del conflicto.

Los avisos de alarma en este sentido no sólo proceden de los Estados, sino también de las instancias europeas, que han venido haciéndose eco de la dimensión de lo que constituye un verdadero problema en nuestros días. Así, en un intento más por generalizar y extender esta práctica pacificadora, la Recomendación $n^{\circ} \mathrm{R}(98)$ I del Consejo de Europa, adoptada en la sesión de 2I de enero de 1998, sobre la Mediación Familiar de forma específica, sigue exhortando a los jueces de los Estado miembros a buscar una acuerdo entre las partes al inicio del proceso matrimonial o en cualquiera de sus fases. Reconoce, además, la distinta función que, para conseguir tales fines, tienen el abogado y el mediador en este tipo de procesos matrimoniales y, así, sus funciones pueden ser complementarias entre sí e, incluso, en algunos casos coincidentes, pero sólo cuando un letrado cuente con formación como mediador especialista en la resolución de conflictos familiares —especial preparación que le dote de una cualificación para desempeñar esta función en el proceso sin olvidar los conocimientos propios de su profesión-, podrá actuar como tal, siempre dentro de las líneas permitidas por el concreto ordenamiento jurídico de cada Estado.

Comprobado que el sistema judicial, a lo largo de su desarrollo, no da siempre respuesta a todos los conflictos que se originan en el ámbito familiar ${ }^{8}$, parece lógico que pueda acudirse a un procedimiento como la mediación, cuyo signo distintivo es que las partes mantienen el control de su resultado. Contraria a la importación de soluciones prefabricadas estándares, la mediación procura el diseño de acuerdos a medida para cada caso, minimizando el conflicto y sus consecuencias negativas'.

De acuerdo con ello, la mediación puede definirse como aquella intervención del mediador que busca ayudar a las partes a enfrentarse al conflicto, abriendo nuevas vías de diálogo, y a encontrar una solución. El mediador carece de poder de decisión y se mantiene neutral en todo momento; extremos éstos que permiten diferenciar su actuación del resto de fórmulas autocompositivas y heterocompositivas de resolución de conflictos.

La mediación intraprocesal, que ahora nos interesa, trata de buscar una propuesta diferente en el ámbito de los procesos matrimoniales, de acuerdo a sus propias leyes y en atención a la propia singularidad de los problemas señalados. Mediante la intervención de una tercera parte, que mantenga su neutralidad a lo largo del procedimiento - $\mathrm{y}$, en definitiva, también del proceso-, se pretende conseguir una mejor resolución que finalice con un acuerdo, que podrá tener lugar, no sólo antes de plantear la acción judicial, sino también durante y después del litigio propiamente dicho.

Si la práctica de la mediación, en todas las relaciones humanas, supone un aprendizaje y un adiestramiento en la resolución positiva de los conflictos ${ }^{\mathrm{IO}}$, su interrelación

\footnotetext{
${ }^{8}$ En palabras de WATZLAwick, P. (Teoría de la comunicación humana, Barcelona: Ed Helder, I995), el sistema judicial convierte «la solución en el problema».

9 Experiencias realizadas en instancias judiciales concluyen en afirmar que las familias que se han sometido a la mediación no solo han obtenido resultados más rápidos, sino que cuentan con un mayor índice de cumplimiento que los resueltos en el proceso judicial.

Io Por ello, la mediación tiene mucho que ver con la educación para una cultura de paz, puesto que cuando solucionamos un conflicto adquirimos la capacidad de solucionar otros futuros conflictos, sea de la misma temática o de otra diferente. Así, cfr. SUARES, M., Mediación, conducción de disputas, comunicación y técnicas, Buenos Aires: Ed. Paidós, I996, p. 53. Téngase en cuenta que, en palabras de Warat, «apostar por el valor pedagógico de la mediación, no solo para la prevención, administración y resolución de los conflictos, sino también como herramienta pedagógica para que el hombre encuentre en el conflicto el sentido de si mismo, la humanización del Derecho, el carácter ético de cualquier vínculo con el otro y un sentido de la ciudadanía, de la democracia y de los derechos humanos que no queden ideológicamente comprometidos con lo heterónomo» (según lo
} 
con el proceso, no solo lleva consigo una importante disminución de costes económicos, temporales, sociales y afectivos, sino que puede ayudar eficazmente a la consecución de la verdad material de cada supuesto conflictivo, cosa que no sucede en los casos de contienda ${ }^{\text {II }}$.

En efecto, sin pretensión de sustitución, sino para aumentar la eficacia de las medidas adoptadas, la mediación puede convertirse en apoyo a la función legalizadora del juez, sustentado en la participación conjunta de la pareja en la toma de decisiones. Permitirá, de esta forma, hacer reversible la pirámide del poder decisorio y colocar a cada elemento del sistema en el nivel que le corresponde, el que más facilite el funcionamiento de la familia ${ }^{\text {I2 }}$.

Como las experiencias piloto realizadas en España se han encargado de demostrar, la mediación y la Administración de Justicia siempre han estado interaccionadas entre sit $^{1^{13}}$. No obstante, la complementariedad entre ambas en el ámbito de los procesos matrimoniales se manifiesta: por un lado, en la posibilidad de que, en cualquier momento del procedimiento, los interesados puedan, a iniciativa propia o a instancia del juzgador, cambiar su forma de resolución del conflicto ${ }^{\mathrm{I4}}$; y, por otro, en que toda mediación con éxito pueda terminar en un convenio de mutuo acuerdo o regulador. Así, la mediación hace posible que, al final del proceso jurisdiccional, sin necesidad de entrar a decidir sobre la mejor opción para cada uno de los desacuerdos, el juez acepte la decisión consensuada, modificando con ello el tipo procedimental contencioso y evitando, en definitiva, las disputas que éste lleva consigo.

A la espera de una regulación estatal de la Mediación Familiar que rija en todo el territorio nacional, y la generalidad de su uso, hoy sólo podemos contar con determinados organismos públicos que, desde el área de bienestar o la asistencia social, han ido apareciendo en el ámbito autonómico con la finalidad de solventar las controversias familiares antes de llegar a los tribunales o con el fin de filtrar los conflictos.

Esta actividad legislativa autonómica junto con la creación de servicios públicos puede considerarse importante e, incluso, tildarse como ejemplar dentro del cuadro europeo, ya que desde el inicio de esta década, y coincidiendo con la asunción por parte de las Comunidades Autónomas en materia de asistencia social, los Parlamentos Autonómicos han comenzado a aprobar leyes en ese sentido, pero con la limitación de su ámbito y por lo tanto de la materia a que se refieren.

La primera legislación autonómica existente fue la catalana con su Ley de Mediación I/2000, de I5 de marzo, consecuencia de la previsión contenida en la Ley 9/1998, de I5 de julio, del Código de Familia de Cataluña; que también tiene su desarrollo reglamentario, aprobado mediante Decreto 139/2002 de Desarrollo Reglamentario de la ley. Le siguió la Comunidad Autónoma de Galicia que aprobó la Ley 4/200I, de 3I de mayo, de Mediación Familiar, donde se configura esta institución como «una manifestación de una

BELLOSO MARTín, N., «Mediación familiar: experiencias en Latinoamérica», en Congreso Internacional de Mediación Familiar, Valladolid, 3I de mayo y i de junio de 2004, p. I5).

${ }^{\text {II }}$ En tal sentido, CAMPO IZQUIERDO, .A., «La mediación familiar como complemento del proceso judicial de familia», Revista de Derecho de Familia 26, Valladolid, 2005, p. 282.

${ }^{12}$ Cfr. Bolaños, I., «Mediación Familiar en contextos judiciales, en POYATOS, A. (coord.), Mediación familiar . $y$ social en diferentes contextos, Valencia: PUV, 2003, p. I76.

${ }^{13}$ Así, MARTín NÁJERA, T., «La mediación intrajudicial», Cuadernos de Derecho Judicial V, Consejo General del Poder Judicial, 2005, p. 225.

I4 Así, Granados PÉREZ, F., «Mediación y Administración de Justicia», Cuadernos de Derecho Judicial V, Consejo General del Poder Judicial, 2005, p. 70. Considera este autor que dicha interrelación entre mediación y Administración de Justicia aboca a una verdad, a su juicio de Perogrullo: que el acuerdo siempre es preferible a cualquier tipo de proceso contencioso. 
actividad de interés público, promovida por la Junta de Galicia en razón de la indudable utilidad pública». Ese mismo año se aprobó en la Comunidad Autónoma de Valencia la Ley 7/200I; y dos años más tarde, en el año 2003, se reguló la mediación familiar en las Islas Canarias, mediante la Ley de 8 de abril de 2003 , que fue modificada meses más tarde por Ley 3/2005 de 23 de junio. Por su parte, en mayo de 2005, se aprobó la Ley del Servicio Social Especializado de Mediación Familiar por las Cortes de Castilla-La Mancha, y durante el año siguiente se aprobaron la Ley i/2006 de 6 de abril, de Mediación Familiar de Castilla-León, y la Ley I8/2006, de 22 de noviembre, de Mediación Familiar de Baleares. Las últimas dos han sido la Ley I/2007, de 2I de febrero, de Mediación Familiar de la Comunidad de Madrid y la Ley 3/2007, de 23 de marzo, de Mediación Familiar de Asturias, hallándose en trámite las de Andalucía y Aragón.

Parece pues que, con el fin de mejorar la comunicación de las parejas en crisis, proporcionándoles otros instrumentos para mejor relacionarse y conseguir un acuerdo total o parcial respeto al conflicto que mantenían, se ha optado por caminar por la senda de la pacificación, generalizando el uso de la mediación familiar, desde las leyes autonómicas a la reforma de la LEC de 2005 .

\section{Hacia la mediación en los procesos matrimoniales}

\section{I. Especialización y primeras experiencias judiciales}

Ante la progresiva utilización de los procesos matrimoniales y los interminables efectos de los conflictos familiares, que permanecen y se perpetúan en el tiempo aún después de la sentencia judicial, en nuestro país se han buscado diversas soluciones que agilicen los procedimientos y respondan a estos problemas.

En este sentido, pese a su no generalización en todo el Estado, se acudió, en primer lugar, a una primera medida consistente en la especialización de los órganos judiciales, mediante la creación de los Juzgados de Familia ${ }^{15}$. En principio pareció ser éste un buen remedio a los problemas, por responder a la idea, mantenida por el Consejo General del Poder Judicial, de facilitar la unificación de criterios en estas cuestiones, y, sobre todo, a la necesidad de obtener una mayor celeridad en la resolución de las situaciones conflictivas familiares.

Por otra parte, experiencias favorecedoras del resultado de acuerdo en los procesos familiares aparecen en el ámbito de concretos Juzgados de Familia de Barcelona y de Madrid.

En el primero de los dos casos, el Juzgado de Familia número i4 de Barcelona, ya en I989, antes de contar con la adecuada cobertura legal, ayudándose de una interpretación extensiva de la referencia del art. 92 del Código Civil al «dictamen de especialistas», inició programas de mediación intrajudicial. Así, aprovechando la favorable disposición de

\footnotetext{
${ }^{15}$ Los primeros fueron creados por Real Decreto I322/I98I, de 3 de julio, cuyo art. I señalaba: «I. Se crean en las capitales que a continuación se mencionan los siguientes Juzgados de Primera Instancia: Cuatro en Barcelona y Madrid, dos en Bilbao, Sevilla, Valencia y Zaragoza, y uno en Córdoba, La Coruña, Granada, Málaga, Murcia, Palma de Mallorca, Las Palmas de Gran Canaria, Pamplona, San Sebastián y Valladolid». Posteriormente se han ido extendiendo, mediante juzgados de nueva creación, o mediante atribución de competencia exclusiva en este ámbito a los ya creados; como ha ocurrido por Acuerdo del Consejo General del Poder Judicial por el cual se atribuye al Juzgado de Primera Instancia número I de Logroño el conocimiento con carácter exclusivo de los asuntos propios de los Juzgados de Familia.
} 
algunos Jueces y Magistrados, los Equipo de Asesoramiento Técnico de este Juzgado de Familia actuaba siguiendo un procedimiento de mediación, en lugar de aplicar el tradicional protocolo de evaluación pericial, cuando le eran pasados los casos para emitir el oportuno informe a instancia de las partes o del Juez para mejor proveer ${ }^{16}$. Los datos estadísticos de las intervenciones realizadas de I989 a I998 muestran cómo en los 583 casos sometidos a mediación, se obtuvieron un 74\% de acuerdos (de los cuales un 53\% versaron sobre el régimen de visitas y un $26 \%$ en relación a la guarda y custodia de los hijos menores); esto es, un $20 \%$ más de acuerdos que en el resto de los Juzgados ${ }^{\text {I7 }}$.

Igualmente, otra iniciativa interesante en el ámbito judicial fue promovida por los tribunales de la capital de España. Así, a través de la firma de un convenio de colaboración, los Jueces de Familia de la capital de España (Juzgado de Primera Instancia número 22$)^{18}$ pasaron a tener, a partir de I997, la posibilidad de derivar las parejas en proceso de separación o divorcio al Gabinete de Mediación Familiar de la Universidad Pontificia Comillas de Madrid, con el propósito de que las parejas con hijos menores, inmersas en un proceso de separación, pudieran beneficiarse del proceso mediador. En concreto, en las comparecencias de medidas provisionales de los pleitos matrimoniales, antes de la celebración formal del juicio, el Magistrado preguntaba a las partes por la posibilidad de alcanzar algún acuerdo respecto de los temas en litigio. En el caso de que se observase que podían aproximarse las posturas de los litigantes, el Juez, auxiliado por el psicólogo del Juzgado, presente en el acto como asesor permanente, intentaba facilitar la comunicación entre las partes y sus representantes, señalando los puntos de acuerdo alcanzados o posibles, e intentado aislar aquellos de desacuerdo específico, para procurar que los interesados formulasen propuestas aproximatorias o intermedias al respecto.

En el supuesto de conseguir el acuerdo, los pactos alcanzados entre las partes, con el informe favorable del Ministerio Fiscal en su caso, debían ser aprobados por el juez y plasmados en el acta de la comparecencia, que se entregaba a las partes y que adquiría la consideración de resolución judicial.

\subsection{La mediación familiar en la Ley $\mathrm{I} 5 / 2005$, de 8 de julio}

La promulgación de la Ley I5/2005 de 8 de julio, por la que se modifican el Código Civil y la LEC en materia de separación y divorcio supuso la primera aparición de la mediación en una ley nacional.

En este sentido, y en la línea de la Recomendación $n^{\circ} \mathrm{R}(86)$ I2, del Comité del Ministros del Consejo de Europa, adoptada el i6 de septiembre de I986, que indicaba como tarea principal de los tribunales la búsqueda del acuerdo amistoso entre las partes al inicio del proceso o en cualquiera de sus fases, la Exposición de Motivos de la citada Ley exhorta a nuestros jueces a propiciar el acuerdo entre los cónyuges respecto de las medidas a adoptar, y señala, expresamente, que la intervención judicial debe reservarse para cuando haya sido

${ }^{16}$ Cfr. CASO SeÑal, M., «Reflexiones desde una toga», en Apuntes de Psicología i8 (2-3), Sevilla: Colegio Oficial de Psicólogos y Universidad de Sevilla, 2000, p. 326.

${ }^{17}$ Así lo recoge MARTí BALDellou C., «La Mediación familiar en Cataluña, estado de la experiencia en otoño de 2003», en Congreso Internacional de Mediación Familiar, Valladolid, 3I de mayo y I de junio de 2004, pp. 7I y ss.

${ }^{18}$ Concretamente, cuando del Juzgado de Familia número 22 de Madrid era titular el Ilmo. Sr. D. José Prieto FernándeZ-Layos. Vid. el número 73 (de i999) de la Revista del Colegio Oficial de Psicólogos. 
imposible el pacto entre ellos $^{\mathrm{I}}$. La mediación se reconoce así como el instrumento procedimental, complemento del proceso judicial, alternativa a lo contencioso, no a lo jurídico ${ }^{20}$, que puede resolver los conflictos matrimoniales que culminan en un proceso, donde la tutela de los derechos que se lleva a cabo de modo inmediato puede verse mejorada por la revalorización de las partes en conflicto. Como lo hicieron hasta que se produjo la ruptura, se trata de que los cónyuges puedan resolver por sí mismos sus controversias $y$, ayudados por un mediador, consigan traducir su conflicto emocional al lenguaje jurídico.

Por su parte, la Disposición Final Primera de la Ley 15/2005 modifica la LEC e incluye la mediación como un instrumento a utilizar en el seno de la regulación de los procedimientos matrimoniales. En concreto:

$\left.\mathrm{I}^{\circ}\right)$ La mediación aparece, en primer lugar, en los preceptos que regulan el procedimiento contencioso, donde se incluye una nueva regla $7^{\text {a }}$ en el art. 770 LEC: «Las partes de común acuerdo podrán solicitar la suspensión del proceso de conformidad con lo previsto en el art. $19 \cdot 4^{2 \mathrm{I}}$ de esta Ley, para someterse a mediación ${ }^{22}$.

$2^{\circ}$ ) También se redacta de nuevo el apartado 2 del art. 77I, en la comparecencia de las medidas provisionales, exhortando ahora a los tribunales a intentar «un acuerdo entre las partes».

$\left.3^{\circ}\right)$ Por último, se otorga una nueva redacción al apartado 2 del art. 777 LEC, en relación con los documentos que deben acompañar a la demanda en los procesos consensuales. Textualmente se dice ahora: «(...) incluyendo, en su caso, el acuerdo final alcanzado en el procedimiento de mediación familiar».

Finalmente en su Disposición Final Tercera, la Ley dice que: «El Gobierno remitirá a las Cortes un proyecto de ley sobre mediación basada en los principios establecidos en las disposiciones de la Unión Europea, y en todo caso en los de voluntariedad, imparcialidad, neutralidad y confidencialidad y en el respeto a los servicios de mediación creados por las Comunidades Autónomas».

Ahora bien, mientras la Ley de Mediación Familiar no sea una realidad, se plantean distintos interrogantes acerca de su tramitación que conviene resolver. Así, por ejemplo: ¿en qué momento del proceso se puede acudir a la mediación?; ¿quien ha de llevar

\footnotetext{
I9 Concretamente, en palabras del legislador, «Con el fin de reducir las consecuencias derivadas de una separación y divorcio para todos los miembros de la familia, mantener la comunicación y el diálogo, y en especial garantizar la protección del interés superior del menor, se establece la mediación como un recurso voluntario alternativo de solución de los litigios familiares por vía de mutuo acuerdo con la intervención de un mediador, imparcial y neutral (...) De esta forma, las partes pueden pedir en cualquier momento al Juez la suspensión de las actuaciones judiciales para acudir a la mediación familiar y tratar de alcanzar una solución consensuada en los temas objeto de litigio».

${ }^{20}$ Cfr. Granados PÉReZ, F., «Mediación y Administración de Justicia», en Cuadernos de Derecho Judicial V, Consejo General del poder Judicial, 2005, p. 7I.

${ }^{21}$ Art. I9.4 LEC: «Asimismo, las partes podrán solicitar la suspensión del proceso, que será acordada, mediante auto, por el Tribunal siempre que no perjudique al interés general o a tercero y que el plazo de la suspensión no supere los sesenta días».

${ }^{22}$ Según MEdinA SuÁREZ, I., y ALES, J. («La mediación familiar como instrumento de protección de la familia al amparo de la nueva ley española de divorcio», Ponencia presentada en la VI Conferencia Iberoamericana sobre Familia en Cuba, septiembre de 2005, http://www.solomediacion.com), el primer paso para un mayor derecho de autodeterminación en la legislación estatal ha sido la introducción de este apartado $7^{\circ}$, que reconoce a la mediación dentro del proceso familiar, y que para su desarrollo deberá ir acompañado en la práctica de medios que la hagan posible.
} 
a cabo este procedimiento?; ¿deberá atribuirse a una persona física o podrá acudirse a una persona jurídica?, ¿deberá ser un mediador único?; ¿deberá tener naturaleza pública o privada?; ¿con que preparación deberá contar para ello?; ¿cómo habrá de llevarlo a cabo?...

\section{Ubicación procesal del procedimiento de mediación}

Una vez configurada la mediación como un procedimiento intraprocesal que puede ser utilizado por todos aquellos que deben acudir al proceso matrimonial, y que, en definitiva, les permite mantener su poder de decisión en las relaciones que les son más propias, las familiares, se plantea el problema de su ubicación procesal. Esto es; de conformidad con lo anteriormente señalado acerca de la relación entre el procedimiento de mediación familiar, en supuestos de ruptura conyugal, y los procesos matrimoniales, se nos suscita la duda de si el inicio del primero puede darse, en referencia al concreto proceso matrimonial, antes de haber comenzado, una vez se ha iniciado o, incluso, cuando ya ha finalizado.

Y, concretando más todavía, cabe plantearse los trámites procesales a seguir para dar cumplimiento al inicio y desarrollo de la mediación en los distintos procedimientos. Esto es, en el proceso de mutuo acuerdo del art. 777 LEC; durante la tramitación del proceso contencioso del art. 770; en relación a los procedimientos de adopción de medidas provisionales, antes o tras la admisión de la demanda, y de modificación de las medidas aprobadas definitivamente; y durante la ejecución de la sentencia dictada en tales procesos.

\section{I. Momentos de inicio del procedimiento}

En referencia a la estructura básica de los procesos matrimoniales, la mediación puede solicitarse en tres momentos: a) previamente al proceso; b) durante el proceso; y c) cuando éste ha finalizado.

a) Previo al proceso matrimonial. En los preliminares, las partes pueden estar de acuerdo en plantear un proceso matrimonial de mutuo acuerdo cuando se trate de la separación y el divorcio -quedan fuera los procesos de nulidad matrimonial-, pero el resto de decisiones siguen siendo controvertidas. Aquí la mediación, prevista por el legislador al incluirla junto a la elaboración del convenio regulador, se convierte en una medida para lograr los acuerdos antes de iniciar la demanda judicial. Así lo menciona, por ejemplo, el art. I0.2 de la Ley 3/2007, de 23 de marzo, de Mediación Familiar de Asturias.

b) Durante el proceso matrimonial. Las determinaciones legales de la reforma citada también la incluyen en la tramitación del proceso, reconociendo la facultad del juzgador para suspenderlo tras la solicitud de las partes para recurrir a un procedimiento de mediación. Se trata de una posibilidad que se prevé en todas las leyes de mediación familiar autonómicas, que remiten siempre en este punto a la legislación procesal, como el art. i6 de la última de las leyes de mediación familiar hasta la fecha, la Ley asturiana I/2007, de 2I de febrero, que dispone: «Cuando existan actuaciones judiciales en curso, las partes, de mutuo acuerdo, podrán acudir a la mediación familiar de conformidad con lo dispuesto en la legislación procesal».

c) Finalizado el proceso jurisdiccional. En la línea de prevenir y paliar los incumplimientos de este tipo de resoluciones judiciales, que las estadísticas señalan muy elevado, el procedimiento de mediación puede llevarse a cabo a pesar de la finalización del proceso judicial. 


\section{2. Ámbito procedimental de la mediación}

3.2.I. La mediación en el marco del proceso contencioso.

El nuevo ordinal $7^{\circ}$ del art. 770 LEC permite la suspensión del proceso familiar para recurrir al procedimiento de mediación, si bien en él no se señala en que fase de ese proceso puede tener lugar dicha remisión. Ante esta ausencia de desarrollo legal, estimamos que la intervención podría plantearse en casi cualquier trámite del procedimiento.

No obstante, puede parecer difícil que en el proceso contradictorio pueda llegarse a un acuerdo tras la práctica de las pruebas, pero la supresión de la separación causal ha abierto nuevas posibilidades. Esta reforma, abogada por la mayoría de los autores que se han ocupado de la mediación, facilita el que, tras el resultado de las pruebas practicadas, las partes perciban de otra forma la necesidad de regular su futuro, lo que pasa por poner solución al conflicto, y por no seguir cuestionando su pasado ${ }^{23}$.

Por otro lado, con anterioridad a la reforma de 2005 , como ya hemos visto, se ha procedido en algunos casos a convertir la prueba pericial en un procedimiento de mediación, en lugar de aplicar el tradicional protocolo de evaluación pericial en casos que son examinados por el Equipo Técnico del Juzgado, para emisión del oportuno informe ${ }^{24}$. No obstante, esto plantea un problema en todos aquellos en casos en los que de esta intervención no resulte un acuerdo y el convenio posterior, en los Juzgados en los que sólo se cuenta con un único Equipo psíco-social. Puesto que el especialista tiene un deber de confidencialidad respecto del contenido del procedimiento mediador, ello le ha de impedir emitir con imparcialidad el informe pericial ${ }^{25}$ que, ante el fracaso de la mediación, deberá practicarse como medio de prueba.

\subsubsection{La mediación en el marco del proceso de mutuo acuerdo}

En su nueva redacción, el apartado 2 del art. 777 LEC incluye «el acuerdo final alcanzado en el procedimiento de mediación familiar» como «documento a acompañar a la demanda en los procesos consensuales de separación y divorcio».

Ante el silencio sobre el contenido de este acuerdo de mediación, la controversia se plantea en estas sede debido a que parece ser tan completo el contenido del convenio regulador, previsto en los arts. 8I y 86 del Código Civil, y el art. 90 del mismo texto, que son muy pocos los aspectos de las relaciones derivadas del matrimonio que no se comprendan en los ahí señalados. Esto es, los aspectos recogidos en el siguiente listado:

«I. El cuidado de los hijos sujetos a la patria potestad de ambos, el ejercicio de ésta y, en su caso, el régimen de comunicación y estancia de los hijos con el progenitor que no viva habitualmente con ellos. Incluyendo el régimen de visitas y comunicación de los nietos con sus abuelos.

${ }^{23}$ Cfr. CASO SEÑAL, M., «Reflexiones desde una toga», cit., p. 326.

${ }^{24}$ Como relata IBÁÑEZ VAlverde, V. («Mediación Familiar Intrajudicial», Papeles del Psicólogo 73, junio de 2003, http://www.cop.es/papeles/vernumero.asp?id=832) ya antes de la reforma legal habían existido procedimientos de mediación intraproceso.

${ }^{25}$ Vid. CASO SeÑAL, M., Loc. cit, p. 326. 
2. La atribución del uso de la vivienda y ajuar familiar.

3. La contribución a las cargas del matrimonio y alimentos, así como sus bases de actualización y garantías en su caso.

4. La liquidación, cuando proceda, del régimen económico del matrimonio.

5. La pensión que conforme al art. 97 correspondiere satisfacer, en su caso, a uno de los cónyuges.»

Ahora bien, existe tal complejidad y variedad en las relaciones familiares, que se suscitan y seguirán suscitándose muchos problemas en torno a muy variadas cuestiones que pueden tener difícil encaje en el enumerado contenido del convenio regulador y que sólo gracias a la interpretación ocurrente y extensiva de los tribunales se han visto incluidas en él. Basta mencionar las peculiares atribuciones de la custodia de los animales domésticos, que en algunos casos se comparten, habiéndo llegado a distribuirse entre los cónyuges los pertinentes paseos.

A partir de la reforma de 2005 , estos aspectos pueden ser introducidos en el acuerdo de mediación, y no sólo para su determinación, sino también para ayudar a entender al Juez las medidas adoptadas por los cónyuges.

Superada esta cuestión, otro problema que plantea el nuevo régimen es que el art. 777 LEC prevé la presentación con la demanda inicial de dos documentos: el convenio regulador y el acuerdo alcanzado en la mediación, si se ha acudido a ella. Sin embargo, ¿no serán ambos documentos redundantes? Si los dos documentos contienen los mismos aspectos y los repiten, ¿no será innecesario uno de ellos?

Indudablemente, dada la obligatoriedad de la presentación del convenio regulador, de conformidad con lo previsto en los arts. 777 y 269 LEC, éste no podrá faltar nunca, ya que sin él no es posible la tramitación del procedimiento, ni tampoco la resolución judicial que le ponga fin, que deberá estar basada en el acuerdo aportado por las partes ${ }^{26}$.

En nuestro criterio, el acuerdo del procedimiento de mediación deberá trasladarse siempre al convenio regulador, de cuyo origen y gestación nunca se ha ocupado la ley.

Solamente cuando el acuerdo de mediación contenga pactos parciales —el desacuerdo entre las partes solo existe sobre determinados aspectos- también éste podrá acompañarse a la demanda como un elemento de convicción, para que el Juez interprete el contenido del convenio, que es, insistimos, el documento que nunca debe faltar. Igualmente, también, podría ser incluido cuando se establezcan pactos, como los antes descritos, sobre esas relaciones familiares peculiares que no encajan de forma tajante en los conceptos legales, pero sí hacen referencia a las relaciones originadas en su seno, y que tan numerosos son en la casuística familiar.

Ahí, por ejemplo, están las tan habituales relaciones del esposo de una madre con un hijo pequeño de una relación anterior, con el que ha convivido durante años y que, cuando llega el momento de la ruptura con la esposa, no tiene posibilidad legal de establecer un derecho recíproco de visitas y contacto con ese menor, al haber sido solo el esposo de su madre ${ }^{27}$ o las compensaciones en las pensiones de alimentos de los hijos, tan

${ }^{26}$ Vid. Asencio Mellado, J. M., «La reforma de los procesos matrimoniales por la Ley I5/2005 de 8 de Julio», en Práctica de Tribunales 23, Madrid, 2006, p. 22.

${ }^{27}$ Cfr. SARIEgo Morillo, J. L., «Mediación intrajudicial o mediación extrajudicial», en Apuntes de Psicología I8 (2-3), Sevilla: Colegio Oficial de Psicólogos y Universidad de Sevilla, 2000, p. 366. 
mal acogidas tradicionalmente por los representantes del Ministerio Fiscal. La respuesta a esas demandas familiares sería el acuerdo adoptado en el procedimiento de mediación, que ya puede ser presentado en el proceso para su sanción judicial.

\subsubsection{La mediación en el trámite de medidas provisionales}

También durante la fase de medidas provisionales, donde se determinan por primera vez las posiciones de los contendientes, que comparecen con sus respectivas defensas, y a la que se llega desde muy diversos orígenes - parejas que llevan tiempo separadas sin ningún tipo de acuerdo, o con acuerdos parciales, parejas que comparten todavía el domicilio familiar, en situaciones de gran enfrentamiento, etc.- , podrá plantearse la posibilidad de acudir a la mediación. Precisamente por el carácter verbal e inmediato del acto, el Juez podrá examinar las pruebas propuestas por cada parte y percibir mejor dicha posibilidad de la mediación ${ }^{28}$.

En el marco de la actual regulación, el art. 77I LEC, en su párrafo segundo, ha incluido la posibilidad de llegar a un acuerdo para fijar esas medidas, acuerdo al que el juez puede exhortar a las partes en la misma comparecencia judicial, que sigue a toda solicitud de medidas provisionales. La dificultad subyace aquí en mantener el breve transcurso de tiempo que la ley ha establecido para la solución de estos incidentes ${ }^{29}$, compatibilizándolo con el concedido para llevar a cabo la mediación; el cual si se dilata en el tiempo puede desfigurar la esencia y finalidad de estas medidas.

Antes de la reforma, determinados Juzgados de Familia habían utilizado la mediación como una medida más, incluida en el auto judicial de resolución del incidente, considerando que también en ese trámite, al poner en práctica las medidas dictadas por el Juez, las partes podrían realizar una valoración de ellas, para después proponer otras distintas o mantenerlas. La experiencia demostró que cuando estas medidas se tomaban como una referencia sobre la que trabajar, más que como una imposición que cumplir, las parejas podían ser capaces de matizarlas y adaptarlas a su realidad ${ }^{30}$.

Con posterioridad a la reforma de 2005 , ya puede remitirse a las partes a un procedimiento de mediación para intentar conseguir el acuerdo como finalidad específica de esa comparecencia anteriormente descrita, quedando claro que se producirá la suspensión del procedimiento tendente a la adopción de las medidas. En igual sentido, el conflicto subyacente puede ser remitido a la mediación cuando se soliciten medidas con la presentación de la demanda o cuando se pretenda la modificación de las acordadas previamente, conforme a los trámites previstos en los arts. 772 y 773 LEC.

\footnotetext{
${ }^{28}$ En este sentido la experiencia relatada por la Magistrada CASO SEÑAL, M. («Reflexiones desde una toga», cit., p. 325) ayuda a una mejor comprensión de la reforma, situando la mediación en un contexto real.

${ }^{29}$ El mismo art. 771.3 LEC señala el plazo de diez días para celebrar la prueba que no pudiera tener lugar en el acto del juicio, y en el art. 77I.4 cómo el Juez debe dictar resolución, en forma de auto, en el plazo de tres días.

${ }^{30}$ Así, uno de los primeros profesionales que contribuyeron activamente al desarrollo de los Equipos Psico-sociales de los Juzgados, con reconocida experiencia en este procedimiento intrajudicial, aporta su perspectiva en BILAÑOS, I., «Mediación en procedimiento matrimoniales», en La ejecución en los procesos de familia, publicación del Centro de Estudios Jurídicos, dependiente del Ministerio de Justicia <http://www.cej.justicia.es/pdf/publicaciones/secretarios_judiciales/SECJUDı2.pdf>, p. 4754.
} 


\subsubsection{La mediación en ejecución de sentencia}

Por último, pese a no existir referencia alguna en la reforma de la LEC que se ha ido examinando, no cabe duda de que, como consecuencia del impulso que la mediación ha experimentado con ella, es posible su desarrollo en ejecución de sentencia.

A pesar de que en este momento del proceso el margen de maniobra de las partes y del mediador es sensiblemente inferior al que se produce antes de la sentencia —el contenido de la mediación queda enmarcado por lo dispuesto en ella ${ }^{31}$ - , sin embargo, es en esta última fase donde la mediación puede convertirse en un apoyo a la medida fijada en la resolución judicial, para intentar un acuerdo con un menor costo emocional y económico de la pareja. No olvidemos que, como veíamos, son habituales los incumplimientos sistemáticos de las sentencias, sobre todo en el pago efectivo de las pensiones económicas correspondientes, tanto a los alimentos como a los gastos extraordinarios ${ }^{32}$.

El proceso de ejecución de sentencia en el ámbito de los conflictos familiares con hijos debe resolver dificultades tales como los cambios provisionales de situación (el progenitor que pasa temporalmente por un colapso económico), los incidentes en el desarrollo del derecho de visitas o las controversias en el ejercicio de la patria potestad. Suelen ser casos en los que se produce un hecho nuevo que altera las circunstancias sobre las que se asentaba el precario equilibrio de las relaciones entre los hijos y sus progenitores, y que hacen surgir los problemas más graves en esta materia: el de los regímenes de comunicación y visitas entre los hijos y el progenitor no custodio, de muy difícil solución en la práctica

Si acudimos a esta práctica, hemos de advertir que existen, por un lado, experiencias judiciales que demuestran que cuando ha intervenido el Equipo psico-social del Juzgado solventando estas cuestiones sin la aplicación rigorista de normas procesales, tanto la familia como los Letrados se han mostrado receptivos, obteniéndose un reducido índice de impugnación en claro contraste con la frecuencia que son impugnadas otro tipo de medidas ${ }^{33}$. Aunque, tampoco faltan estadísticas y datos de asociaciones de padres separados que infravaloran y alertan sobre la actuación de los Equipos psico-sociales ${ }^{34}$.

Si bien se han intentado otro tipo de remedios, dado lo reiterado de estos incumplimientos del deber-derecho de visitas, como es el caso de los «puntos de encuentro familiar», creados por la Administración ${ }^{35}$, y que han servido para facilitar un lugar neutral

${ }^{31}$ Cfr. MejÍA, J. F., «La Mediación Familiar», cit., p. I30.

${ }^{32}$ El diario El País publicaba este verano, el dia I8 de agosto de 2006, que «El impago de pensiones (destinadas sobre todo a los hijos) tras la ruptura de las parejas es un delito en alza. Las denuncias se han duplicado con creces entre 1994 y 2004: de 4.336 a 9.136, según la Fiscalía General del Estado». Leído en: http://www.ipfe.org/es

${ }^{33}$ Vid. ORTUÑo MUÑOZ, P., «El dictamen de especialistas como prueba pericial “sui generis" en el Derecho de Familia y la Mediación», Poder Judicial 37, Madrid, 2005, p. 205.

${ }^{34}$ El abogado SARIEGO MORILLO, J. L. («Mediación intrajudicial o mediación extrajudicial», cit., p. 368) alerta sobre este dato y dice que «desde asociaciones de padres separados se da la consigna de evitar al máximo el acudir a estos equipos psicosociales», por lo que pone de manifiesto la dificultad de que se realice la mediación desde este ámbito, señalando igualmente que tampoco las asociaciones de mujeres alientan en ese sentido, porque entienden que las leyes les otorgan más derechos que los que obtendrían en mediación.

${ }^{35}$ Describe SEPúlVedA, M.A. y SERRANO, F. A. («Punto de encuentro familiar: un recurso social alternativo», Apuntes de Psicología I8 (2-3), Sevilla: Colegio Oficial de Psicólogos y Universidad de Sevilla, 2000, p. 375) la innovación que se inició en Valladolid por la asociación APROME (Asociación para la Protección del Menor en los Procesos de Separación de sus Progenitores), entidad sin ánimo de lucro de carácter social y ámbito nacional, fundada en I994, la cual divulgó por 
para el encuentro, estas medidas no dejan de tener un carácter paliativo, sin llegar a resolver definitivamente el conflicto.

En tales casos es posible ponderar el inicio de un procedimiento mediador, que pueda ayudar a establecer un acuerdo ajustado a las nuevas circunstancias, que resuelva el conflicto que todavía, a la finalización del proceso judicial, está latente. Con ella se devolverá al entorno familiar el protagonismo en las decisiones que les afectan, al ser los integrantes de la familia las personas más indicadas para resolver sus disputas ${ }^{36}$.

Por otro lado, muchas veces las sentencias de los procesos matrimoniales se dictan tras la presentación de un convenio de mutuo acuerdo que ha constituido el último de los remedios para no prolongar un conflicto o que es el resultado de aplicar la teoría del «mal menor». De esta forma, la mediación puede originarse también en el momento en que varían las condiciones que se tuvieron en cuenta para dictar aquellas medidas.

En este sentido, resulta muy clara la Ley de mediación familiar de Castilla-La Mancha, la cual en art. 25.2 dispone que los acuerdos resultado de un proceso de mediación familiar «podrán ser utilizados por las partes para modificar un convenio regulador previamente pactado entre ellas o para modificar las medidas adoptadas judicialmente en un proceso» matrimonial. No obstante en tal caso de modificación de medidas adoptadas en un proceso jurisdiccional, las partes deben presentar tales acuerdos al Juzgado para que, a través de su aprobación judicial, quede constancia frente a cualquiera de que se ha producido dicha modificación.

\section{Decisión de acudir a la mediación}

4.I. Iniciativa de las partes.

Acerca de quien debe tomar la iniciativa en el seno del proceso jurisdiccional para acudir a la mediación, existe una importante controversia doctrinal a tener en cuenta. Así, mientras que para algunos autores el principio de que las partes deben ser quienes acudan voluntariamente a la mediación es inmutable, otros han entendido que resulta posible la coexistencia pacífica con el mandato judicial.

No obstante, este punto ha sido resuelto por nuestra regulación procesal, al haber legitimado expresamente a las partes en el art. 770 LEC, pues son ellas las que «de mutuo acuerdo podrán solicitar la suspensión del proceso (...) para someterse a mediación». Del mismo modo, ha permitido también al propio Juzgador, en virtud del párrafo $2^{\circ}$ del art. 77I, en sede de las medidas provisionales, convocar a los contendientes a una comparecencia para llegar a un acuerdo; acuerdo que nada impide que pueda ser alcanzado por la vía de la mediación ${ }^{37}$.

todo el país el concepto del punto de encuentro como un lugar neutral, cuya finalidad es facilitar el cumplimiento de las medidas acordadas por los Juzgados de Familia u otras instituciones, respecto al ejercicio del derecho de visita o relación con el menor y sus familiares.

${ }^{36}$ Vid. CASO SEÑAL, M., «Reflexiones desde una toga», cit., p. 328.

37 Por su parte, el art. 4.3. de la Ley mediación familiar de Galicia, recoge incluso la opción, «conforme a lo previsto en la legislación civil y procesal», de que sea el Juez que está conociendo de un proceso matrimonial el que proponga a las partes, durante su desarrollo, la posibilidad de la mediación. 
Indudablemente, la iniciativa de las partes sigue estando muy presente $y$, de hecho, tras la reforma de 2005 , en el procedimiento de mutuo acuerdo, éstas tienen la vía libre para adjuntar, también documentado, el acuerdo conseguido, junto al tradicional convenio regulador (art. 777 LEC).

Como se observa, todos estos datos denotan un mayor reconocimiento por el legislador a la voluntad de las partes, porque aquí vuelve a corresponderles la decisión de acudir a la mediación en orden a afrontar las relaciones posteriores a la ruptura de su matrimonio. Téngase en cuenta que de nada servirá el instrumento de la mediación si los cónyuges no están de acuerdo. Así, el acatamiento de las sugerencias que se producen en sede judicial —motivado muchas veces por el tradicional temor de las partes, aconsejadas por sus defensas, a oponerse a las iniciativas del juez-, dando a entender una voluntad conciliadora que es ficticia, hará peligrar el acuerdo en la mediación, pudiendo provocar, en definitiva, un recrudecimiento del conflicto y una nueva dilación en su resolución ${ }^{38}$.

\subsection{Decisión judicial}

Una vez comenzado el proceso matrimonial, en la decisión judicial sobre el inicio del procedimiento mediador, el juez deberá valorar la situación en que se encuentran las partes, con vistas a que la remisión a dicho procedimiento no se convierta en un trámite dilatorio del conflicto familiar, uno de los mayores peligros en estas controversias. Para ello, siguiendo la tesis de Haynes ${ }^{39}$, el juzgador deberá considerar varios aspectos: a) que los niveles de conflicto sean realmente moderados; b) que exista una motivación real de las partes para llegar a un acuerdo; y c) que el procedimiento de mediación ofrezca un grado de confianza a las partes.

No obstante, la decisión judicial, propugnada legalmente, aparece acompañada de otro tipo de cuestiones pendientes de resolver. La primera es la de si el juez cuenta con criterios suficientes para detectar por sí mismo si el enfrentamiento de las partes se resolverá en la mediación, o si necesitará para ello la ayuda de los Equipos psico-sociales del Juzgado. Puesto que éstos pueden no ser especialistas en mediación, se siguen sucediendo los interrogantes. Así, cabe plantearse si será necesaria la creación de un cuerpo de mediadores adscritos a los Juzgados, y si será preceptiva, entonces, la presencia de éstos en las comparecencias. En todos aquellos Juzgados que no cuenten con mediadores, ¿donde remitirá el juez a las partes para dicha mediación? Todo ello sin olvidar, además, la cuestión no resuelta de la financiación de este trámite procedimental. Cabe preguntarse cómo se incluirá este gasto en el proceso y a quien ha de corresponder su pago; y, en concreto, si el auto o la sentencia judicial que se dicten deberán contener o no la condena en costas por este concepto. Realmente si la mediación consigue un acuerdo final, consideramos que una de sus conclusiones, como medida de su éxito, podría ser el abono de los gastos que ha provocado la mediación entre las partes, si ésta no ha sido pública o si ellas no contaban con el beneficio de justicia gratuita en el proceso matrimonial; sin embargo, la posibilidad de fracaso del procedimiento mediador acrecienta las dudas que se suscitan

Mientras no exista una ley nacional éstas y otras cuestiones no podrán ser resueltas uniformemente, y solo en aquellas Comunidades Autónomas donde exista una regulación sobre mediación familiar o existan servicios familiares institucionalizados podrán ser solucionadas de forma que no resulte gravosa para las partes.

\footnotetext{
$3^{8}$ Esta práctica habitual en la mayoría de los casos preconizada por los abogados, consecuencia directa de esa confrontación ganador-perdedor en la que han sido educados estos profesionales, es relatada por SARIEGO MORILLO, J. L., «Mediación intrajudicial o mediación extrajudicial», cit., p. 365.

${ }^{39}$ Según señala SARIEGo MORILlo, Loc. cit., p. 368.
} 
Aún con todo, entendemos que uno de los problemas más agudos de este procedimiento es su escasa implantación en sede judicial ${ }^{40}$, lo que denota que debe ser conocido por todos los profesionales del foro ${ }^{4 \mathrm{I}}$, debe ser regulado como tal, y deben ser también todos los agentes aleccionados en su práctica. A nuestro juicio, esto nunca será posible sin la existencia de una regulación estatal, que no solo armonice las regulaciones autonómicas, sino que establezca un marco de referencia de indudable carácter procedimental.

\section{Mediación pública y/o privada}

El legislador, en la reforma de la LEC llevada a cabo mediante la Ley I5/2005 de 8 de julio, no ha precisado el carácter de la mediación; esto es, si la autoridad judicial va a remitir a las partes del proceso a un servicio público — que, como tal, debiera facilitar la Administración de Justicia, a semejanza de los equipos psicosociales o la reciente Oficina de Atención a la Víctima-, si la remisión debe producirse a servicios ya creados en las Administraciones autonómicas, o si el recurso a una mediación privada, llevada a cabo por profesionales liberales, puede dejarse a la elección de los litigantes, con la correspondiente ayuda económica en los casos de reconocimiento del derecho de asistencia jurídica gratuita.

En el Derecho comparado se observa como en algunos países la mediación es considerada un servicio con carácter público, mientras que en otros, como la vecina Francia, tiene carácter privado.

Las primeras leyes autonómicas de nuestro país, que han ido regulando la mediación familiar, no han señalado, tampoco, de una forma clara su naturaleza pública o privada, pero han tendido a compatibilizar el ejercicio de ambas. En algunos casos lo que sí se ha hecho es establecer un control por parte de la Administración, a través de ciertos organismos independientes — como es el Centro de Mediación en Cataluña o el de Valencia - o mediante la inspección de la propia Administración — como ha ocurrido en Galicia, por la propia Consejería competente en materia de familia-.

Por su parte, mientras la Ley mediación familiar canaria deja bien claro que la mediación es privada ${ }^{42}$, la Ley mediación familiar de Castilla-La Mancha, del año 2005, regula un servicio social especializado, incardinado en el sistema público, aunque no excluye, al igual que sucede en las leyes de 2006, de Castilla-León y de Baleares, la

${ }^{40}$ Proyecto de Mediación Familiar promovido desde el Consejo General del Poder Judicial en seis ciudades españolas durante el año 2007, que han incluido puntos de información en la sedes judiciales. Éstas reciben los casos directamente derivados de los Juzgados, para, posteriormente, remitir a las partes — previa decisión voluntaria de éstas, tras recibir la información oportuna- a un procedimiento de mediación, que se lleva a cabo por diferentes servicios de mediación dependientes de las distintas administraciones, como los CAF (Centros de Atención a las Familias) del Ayuntamiento de Madrid.

${ }^{4 \mathrm{I}}$ Desde el Consejo General de la Abogacía Española se han llevado a cabo distintas iniciativas para dar a conocer este procedimiento entre los abogados y demás operadores jurídicos (entre otras, por ejemplo, la Jornada de 22 de febrero de 2007: «Experiencias diversas del abogado ante la mediación en los procesos de familia» o su participación en el Foro de la Justicia donde se promueve la generalización de la mediación para la resolución de los conflictos).

${ }^{42}$ Sobre el particular, CAMPO IZQUIERDO, A. L. («La mediación familiar como complemento del proceso judicial de familia», Revista de Derecho de Familia 26, Valladolid, 2005, p. 292), defiende que «por su experiencia como juez y usuario de servicios públicos los principios que deben regir la mediación son más compatibles con la mediación privada que la pública, sin olvidar él tema de la Asistencia Gratuita». 
existencia de institutos privados, siempre debidamente registrados, o en la del Principado de Asturias de 2007.

Obviamente la mediación privada y la mediación pública pueden ser utilizadas por las partes que inician de mutuo acuerdo un proceso de separación o divorcio (art. 777 LEC). Como ha venido haciéndose, incluso antes de la reforma de 2005 , los cónyuges han podido conseguir el convenio regulador de mutuo acuerdo acudiendo a cualquier tipo de mediación y pueden, asistidos de una única defensa, presentarlo en el correspondiente Juzgado.

No obstante, habida cuenta de que la mediación familiar es utilizada también dentro del proceso para conseguir el mejor acuerdo y el mejor cumplimiento de lo previamente sancionado en una resolución judicial, no debe dejarse de lado la necesidad de una regulación legal, sobre todo en aquellos supuestos en que se acude al procedimiento mediador desde la instancia judicial.

Como el resto de los profesionales que intervienen en el proceso, con independencia de su naturaleza pública o privada, la intervención del mediador debe estar tutelada por el Estado. Máxime cuando, además, la propia Constitución Española, en su art. 39, recoge la obligación de los poderes públicos de asegurar la protección social, económica y -lo que ahora más nos interesa - la jurídica de la familia, no como un derecho fundamental, sino como un principio rector de la política económica y social que informará toda actuación en ese ámbito. A tenor de ello, es preciso que se establezca el régimen legal de la mediación familiar desde el ámbito estatal, para salvaguardar su homogeneidad e impedir las desigualdades por razón de territorio ${ }^{43}$.

Por otro lado, no podemos olvidar que el texto constitucional recoge, a su vez, la iniciativa privada como otro de sus principios rectores, por lo que no parece posible que pueda impedirse por el Estado el ejercicio privado de la mediación, pero sí podrá ser amparada por él.

Se ha podido observar desde la práctica, y así ha llegado a afirmarse ${ }^{44}$, este desconcierto en el desarrollo del sistema es la consecuencia de la implantación de un método sin la definición previa de su contenido inicial. De hecho, en este contexto de controversia entre su carácter público o su carácter privado, algunos autores tienden a denostar lo que consideran «la institucionalización» de la mediación, por cuanto supone, según ellos, «constreñir y restar protagonismo a las características distintivas de la mediación ${ }^{45}$. Se confunde de esa forma, según se ha dicho, mediación con estrategias de mediación utilizadas dentro de una estructura orgánica de la Administración de Justicia, que hacen que la esencia de la mediación se pierda porque al menos una de las partes no se encuentra ahí «voluntariamente» ${ }^{46}$.

Mientras la realidad de la mediación familiar, allí donde ha sido utilizada, sigue permitiendo su carácter tanto público como privado, esta misma realidad nos revela que no todos los Juzgados existentes en España cuentan con Equipos Técnicos adscritos, ni todos éstos son especialistas en mediación familiar, por lo que sería deseable que, en la misma medida que se solicita la especialización de los Juzgados para atender los procesos

${ }^{43}$ En idéntico sentido, Clements RodrígueZ, A. («La mediación familiar: algunas cuestiones relativas a su implantación en el ordenamiento jurídico español», Revista General de Derecho de la Universidad de Granada 4, Granada, 200I, p. 306) señala que no sería justo posibilitar el acceso a un método extrajudicial a los ciudadanos de una determinada comunidad autónoma y no a los de otra.

${ }^{44}$ Así, desde la experiencia de las mediaciones llevadas a cabo en los distintos Juzgados donde ha ejercido, ORTUÑO MUÑOZ, P., «La aprobación de los acuerdos en mediación familiar», cit., p. 292.

${ }^{45}$ En palabras de BERNAL SAMPER, T., «Mediación extrajudicial», cit., p. 43.

${ }^{46}$ Así, SARIEgo Morillo, J. L., «Mediación intrajudicial o mediación extrajudicial», cit., p. 364 . 
familiares, se cuente con mediadores adscritos, que auxilien al Juez en determinadas especialidades, y se ofrezcan como servicio público para las partes.

Indudablemente sería imposible dotar absolutamente a todos los órganos jurisdiccionales de un asesor o equipo de asesores técnicos, por razones de índole simplemente económica y porque, probablemente, no sería tampoco lo más recomendable la creación de un enorme aparato estatal o institucional que eliminase toda posibilidad de ejercicio liberal de la profesión ${ }^{47}$. Y hasta que se produjese esa dotación judicial, en el fondo idílica y poco factible, quedarían sin resolver multitud de problemas, y nos encontraríamos con la infrautilización de los servicios de mediación autonómicos.

Existen, además, otras razones fundamentales para la coexistencia de ambos tipos de instituciones dedicadas a la mediación. Así, aunque tampoco podría hablarse de perdida de imparcialidad en el ejercicio de la profesión si ésta se desenvuelve desde los Juzgados o desde la Administración autonómica, pues tal principio no puede hacerse depender exclusivamente de si se trabaja privada o institucionalmente ${ }^{48}$, siempre habrá sectores de población que sigan pensando en el funcionario-mediador como extensión del Juzgado al que acuden.

Tampoco puede mantenerse que la mediación enmarcada en la Administración de Justicia pierda confidencialidad, ante el temor de ciertos usuarios de connivencia con el Juez. En la práctica, como han confirmado los Equipos psico-sociales, un servicio bien estructurado impide esos riesgos ${ }^{49}$.

Por otro lado, téngase en cuenta que la mediación será de mayor calidad si existe competencia y, además, la mediación privada ofrece ciertas ventajas, ya que el plus de su independencia obliga a demostrar su mejor hacer, sin poder alegar exceso de trabajo, dilaciones, $u$ otros motivos de esa índole, para conseguir los mayores éxitos, que radican en el mayor número de acuerdos conseguidos y en su posterior cumplimiento ${ }^{50}$.

Todas estas consideraciones nos hacen concluir que el Juez no debe estar condicionado ni por la existencia de la mediación pública ni por el ejercicio de la privada, sino que podrá indicar a las partes las posibilidades con las que cuentan. Lo contrario sería atentar contra el principio de libertad, que en el desarrollo de este procedimiento se ha visto especialmente protegido, y que radica en su misma esencia de mantener la capacidad de decisión de las partes en conflicto.

De acuerdo con ello, la mediación debe ser pública y privada, pero los poderes públicos no solo deben velar por la difusión de este procedimiento y reglamentar su práctica. Como se señalará más adelante, existe la perentoria necesidad de un Registro en

${ }^{47}$ Exponen esta opinión De LuIS CABARGA, P., e IBÁÑEZ VAlVERdE, V.J. («Juzgados de Familia: Psicología Jurídica o Justicia Psicológica», Papeles del Psicólogo 30, Madrid: Consejo General de Colegios Oficiales de Psicólogos, I987, http://www.cop.es/papeles/vernumero.asp?id=323) donde se refirieren a la función de los Equipos psico-sociales del Juzgado, trasladable a los equipos de mediación. Según ellos, «dado que en el momento actual es impensable la generalización absoluta de los servicios institucionales de asesoría a los Juzgados y Tribunales, parece lo más lógico establecer un sistema mixto, tan interconectado como sea posible, aprovecharlo y sirviendo en lo que quepa a las demás redes de servicios sociales, tanto privadas como institucionales».

${ }^{48}$ En este sentido, está demostrado que los peritos, como especialistas auxiliadores de los Juzgados en determinadas causas, pueden llevar a cabo su función con perfecta imparcialidad desde la práctica privada; y su trabajo ante los tribunales es, no sólo recomendable, sino imprescindible.

49 Así, Coy Ferrer, A., Apuntes de Psicología i8 (2-3), Sevilla: Colegio Oficial de Psicólogos y Universidad de Sevilla, 2000, p. 2II.

${ }^{50}$ Cfr. SARIEGo Morillo, J. L., «Mediación intrajudicial o mediación extrajudicial», cit., p. 372. 
cada Comunidad Autónoma y la indiscutible exigencia de un Código deontológico nacional. Además, para garantizar el pleno acceso a este procedimiento, tendrá que ofrecerse como un servicio de asistencia social — tal y como ha sido en la mayoría de las Comunidades Autónomas, tras la asunción de competencias en Bienestar Social y Asuntos sociales- y tratar de coordinarlo con los Juzgados y Tribunales ${ }^{51}$. Es esta combinación de caracteres, en definitiva, la que logrará, además, la plena efectividad del reconocimiento del derecho de asistencia jurídica gratuita cuando sea concedido en relación a estos procesos familiares.

La mediación es una profesión, y lo realmente importante es que, ya se integre en la Administración de justicia o en los servicios sociales autonómicos, deberá contar con la misma formación que la mediación privada ejercida como profesión liberal independiente o integrada en una asociación. De acuerdo con ello, seguimos insistiendo, no debe oponerse mediación pública a mediación privada, al tratarse de dos aspectos complementarios de una misma práctica profesional, que deberá contar fundamentalmente con la misma formación ${ }^{52}$.

\section{La figura del mediador}

De acuerdo con lo expuesto en el apartado anterior, y ante el silencio todavía del legislador en este punto, toca ahora realizar consideraciones en referencia a la figura del mediador familiar. En concreto, a la función que está llamado a cumplir, a los conocimientos y la formación que se le exige, a su configuración como equipo multidisciplinar, y al código deontológico al que debe verse sometido.

\section{I. Función del mediador familiar}

La intervención del mediador familiar como profesional al que acudirán las partes para llegar a un acuerdo, que pueda ser presentado en cualquier proceso matrimonial, consiste en moderar, propiciando actitudes colaboradoras, para conseguir, a través de estrategias, que las partes puedan debatir todas las cuestiones conflictivas entre ellas, y posibilitar así que surjan los acuerdos ${ }^{53}$.

Esa función puede llevarse a cabo con distintos métodos que son esencialmente psicológicos, y que en un estudio llevado a cabo por Becker-Haven a principio de los años ochenta $^{54}$, se agruparon en cuatro modalidades:

1) Modalidad educativa. El objetivo de la mediación de los seguidores de este modelo de intervención es el de facilitar a los clientes información objetiva sobre temas legales, educativos, psicológicos, de negociación, etc.; para que las partes que acuden a la

${ }^{51}$ A semejanza del acuerdo entre el Ministerio de Justicia y el Consejo General de la Abogacía para la Asistencia Letrada Gratuita y el turno de oficio, o el Protocolo de colaboración en el ámbito de la mediación familiar de II de mayo de 2005 entre los Departamentos de Justicia y Bienestar Social de Cataluña.

${ }^{52}$ Vid. Coy Ferrer, A., Apuntes de Psicología, cit., p. 2II.

${ }^{53}$ En ese mismo sentido, GARCÍA GARCÍA, L. (Mediación Familiar: Prevención y alternativa al litigio en los conflictos familiares, Madrid: Ed. Dykinson, 2003, p. 153), para describir ese papel de moderador del mediador familiar, añade que utilizando la dinámica del proceso establecerá normas básicas para confrontar ideas.

${ }^{54}$ Según sostiene ARMAS HeRnÁndeZ, M., «La mediación en la resolución de conflictos», Revista Educar 32, Barcelona, 2003, p. I28. 
mediación, con el bagaje que les aporta una información que los dos quieren simultáneamente, negocien sus propios acuerdos.

2) Modalidad racional-analítica. En este modelo, el proceso mediador, muy pautado y basado en protocolos de negociación asistida, va conduciendo a los clientes desde el primer punto en que se encuentra su negociación hasta el punto final de plasmación de un acuerdo satisfactorio. El mismo modelo es aplicado tanto a temas de custodia de hijos como a negociaciones sobre la distribución de bienes o la utilización de la vivienda conyugal.

3) Modalidad terapéutica. El tema emocional no es pasado por alto a lo largo de las sesiones de mediación, sino que en ellas se abordan las emociones y los sentimientos (positivos, negativos, complejos...) como parte de la intervención mediadora, con el objetivo de que no sean un obstáculo para llegar a acuerdos o, simplemente, como parte integrante del proceso mediador.

4) Modalidad normativo-evaluativa. El rol del mediador en este modelo es claramente directivo. El mediador es consciente de que su control del proceso está influyendo directamente en el contenido de la mediación. Los mediadores que utilizan este modelo se sienten legitimados para seguirlo, porque creen que sólo con este rol pueden ayudar a que se logre el «mejor beneficio» de sus clientes. Siguen este modelo porque, en su opinión, les ayuda a cumplir el requisito ético de intentar un equilibrio de poder entre las partes o porque, simplemente, les permite responder a las demandas de los clientes.

Por su parte, todas las definiciones de mediador siguen esa línea descriptiva de funciones, como facilitador, negociador, transmisor, agente de la realidad, creador de atmósferas, etc., que no dejan de ser aptitudes del mediador y que están directamente relacionadas con otro tipo de ciencias (la Psicología, la Sociología, etc.) que nada tienen que ver con el punto de partida de este trabajo: la ordenación legal de la mediación.

La aproximación que se lleva a cabo desde la perspectiva de la aprobación judicial de los acuerdos de mediación, es quizás la más acertada, al ir eliminando de forma negativa lo que no es el mediador para saber quién es. Así, en principio, en palabras de Ortuño Muñoz, el mediador no es un árbitro porque no ha de decidir, ni es un asesor, ya que no debe aconsejar, ni es un conciliador, ni un terapeuta familiar, como tampoco participa en el conflicto directamente, ya que tendría un poder del que carece ${ }^{55}$. Igualmente el mediador ni es un asesor del Juez ni es un perito, puesto que la comunicación a propiciar entre las partes no sería sincera si terminara informando al tribunal. Por último, el mediador nunca será un fedatario, ni un testigo, ni uno de los abogados encargado de asesorar a las partes, puesto que deberá estar sujeto al principio de confidencialidad.

\subsection{Conocimientos legales y formación del mediador}

El mediador familiar, además de una disposición especial a favorecer el dialogo, para lo que necesita una formación especifica en las técnicas señaladas, deberá, indudable e inexcusablemente, ser un buen conocedor del ordenamiento jurídico. Es aquí donde coincidimos con aquellos autores que defienden al mediador como un profesional del Derecho ${ }^{56}$, porque es el único que con su ciencia y experiencia podrá hacer caminar el

\footnotetext{
${ }^{55}$ Como señala, con cita de RIPOLL-Millet, el Magistrado ORTUÑo MUÑOZ, P., «La aprobación de los acuerdos en mediación familiar», cit., p. 292.

${ }^{6}$ Así, GARCíA GARCÍA, L. (Mediación Familiar: Prevención y alternativa al litigio en los conflictos familiares, cit., p. I54), que aboga por la distinción entre su actuación como abogado y la intervención como mediador, pues puede dar lugar a equívocos con las partes que pueden identificar su asesoramiento con la imparcialidad predicable a todo mediador.
} 
procedimiento de mediación y sus resultados en el adecuado marco legal. Las razones para ello son varias.

En primer lugar, se debe tener en cuenta que nos estamos refiriendo, en todo momento, al mediador familiar que interviene en el proceso jurisdiccional a iniciativa de las partes o del tribunal para conseguir un arreglo, lo que entraña un ineludible conocimiento de cómo funcionar en el foro. Consideramos que su formación jurídica no hace peligrar su naturaleza neutral sino, al contrario, será la mejor garantía de que los acuerdos adoptados pueden ser sancionados por el juzgador.

En segundo lugar, el profesional del Derecho es el único que, como interviniente en los procesos judiciales, cuenta con la experiencia suficiente para demostrar que el proceso contencioso no es el más adecuado para afrontar las disputas que tienen una clara base relacional. Aspecto éste que lleva consigo la necesidad de una práctica previa, siempre unida a su capacitación como mediador.

En efecto, el mediador tendrá que contar con una formación específica y añadida a su conocimiento legal, que le permita utilizar las técnicas propias de la mediación, y completada inexcusablemente con la práctica en ese campo.

Partiendo de esas premisas corresponde ahora al legislador la reglamentación de la actividad del mediador, la formación con la que debe contar y, en definitiva, todos los aspectos de una disciplina profesional, que en nuestro país es nueva.

En la actualidad, solo contamos con las regulaciones autonómicas que establecen unos requisitos básicos para ejercer. Así, a la exigencia de determinadas licenciaturas (Derecho, Psicología o Trabajo Social; con la particularidad de la Leyes de mediación familiar valenciana y madrileña que admiten todo tipo de licenciados universitarios), se añade una formación específica en las técnicas de mediación, junto a la necesaria inscripción en algunas Comunidades Autónomas en un registro público.

En este contexto, es Galicia, vía Reglamento, la que dispone de una normativa que podría servir de modelo al legislador nacional, en su art. 3.2 del Decreto I59/2003, de 3I de enero, por el que se regula la figura del mediador familiar. En concreto, exige para inscribirse en el registro:

a) Titulación en Derecho, Psicología, Pedagogía, Psicopedagogía, Trabajo Social o Educación Social.

b) Haber desarrollado, al menos durante los dos años inmediatamente anteriores a la solicitud de habilitación para la inscripción, actividades profesionales en el campo psico-socio-familiar.

c) Estar en posesión de las licencias o autorizaciones pertinentes para el ejercicio de su actividad profesional y, en su caso, inscrito en su colegio profesional.

Esta previsión resulta muy completa, al combinar la titulación universitaria de marcado carácter teórico con la experiencia y destreza que sólo da la práctica en estos problemas familiares, y cuya resolución nunca debe ser abordada sin contar con experiencia en este ámbito.

La indeterminación del perfil profesional del mediador puede resultar un campo abonado para los que buscan un nueva salida profesional ${ }^{57}$, peligro inminente que podría

\footnotetext{
${ }^{57}$ Así, afirma Villagrasa AlCAIDE, C., y VAll RiUs, A. («La mediación familiar en Cataluña: análisis sistemático de la ley I/200I, de I5 de marzo», en
} 
evitarse con el cumplimiento del mandato contenido en la Disposición Final Tercera de la Ley I5/2005, que exhorta al Gobierno a redactar un proyecto de ley sobre mediación en un plazo ya ampliamente sobrepasado. Dada la importancia de los conflictos a intervenir, y, máxime cuando desde todos los ámbitos se ha coincidido en insistir especialmente en el valor de la experiencia ${ }^{58}$, tanto el procedimiento de mediación como el perfil de mediador deberían encontrarse debidamente reglamentados.

\subsection{Mediador individual y entidades de mediación}

Otro de los problemas que plantea la ausencia de una regulación legal son las dudas acerca de si la mediación debe realizarse por un mediador único o puede, por el contrario, desarrollarse a través de equipos multidisciplinares.

Este aspecto no se encuentra uniformemente regulado por las distintas leyes autonómicas y, así, unas han optado por sistemas individuales, como Galicia y Cataluña, mientras que otras, como Valencia, Canarias, Baleares o Asturias, establecen un sistema mixto. Estas hablan de centros o entidades de mediación junto al mediador como persona física. En concreto, el art. II de la Ley mediación familiar valenciana lleva por rúbrica «del número de personas mediadoras», y admite esa doble posibilidad, mientras que el art. 6 de la Ley mediación familiar canaria, bajo el epígrafe «de las entidades de mediación», admite la posibilidad individual y la de los mediadores integrados en personas jurídicas, utilizando de forma expresa la expresión «equipos multidisciplinares» ${ }^{59}$. Igualmente, las normas de Castilla-La Mancha y la de Castilla y León prevén la doble posibilidad, si bien parecen inclinarse por estos equipos multidisciplinares.

Por otro lado, la doctrina discrepa sobre la virtualidad de cada una de estas opciones. Así, frente a un sector que considera que la confidencialidad se vería perjudicada por la intervención de varios sujetos, y las partes podrían ver comprometida su confianza por la sucesión de personas mediadoras, que podrían dificultar su personal implicación, desde la práctica de los Juzgados, una vez valorada la naturaleza de los conflictos sometidos a mediación y las distintas esferas de conocimiento exigidas para resolverlos, se estima necesario un sistema de equipos multidisciplinares, donde puedan garantizarse los debidos conocimientos, jurídicos, psicológicos, psicosociales y de las técnicas de mediación ${ }^{60}$. Téngase en cuenta que la mediación es un campo de trabajo considerado unánimemente multidisciplinar, donde tienen cabida la Psicología, la Abogacía, el Trabajo Social e, incluso, la Medicina ${ }^{6}$, lo que determina que sea más difícil hacer coincidir todas esas formaciones en una sola persona. Indudablemente, los equipos presentan la ventaja de que, sean públicos o privados, existan más posibilidades de ir adquiriendo la práctica y la experiencia

<http://www.gencat.net/justicia/temes/entitats_juridiques/mediacio/publicacions_i_articles/analisi/ index.html>) que la reciente implantación de este proceso extrajudicial de resolución de conflictos en nuestro país abre una nueva salida profesional para los abogados con capacidad negociadora.

${ }^{58}$ Desde otro ámbito profesional como la Psicología, se ha señalado la misma necesidad de la experiencia para asegurar una buena parte del éxito de la mediación. Vid. BAILÓN CASANOVA, A., «La mediación familiar: un nuevo campo para los profesionales de Psicología», Hojas informativas de los psicólogos de Las Palmas 36, Colegio Oficial de Psicólogos de Las Palmas, abril 200I, p. 20.

${ }^{59}$ Cfr. CAMPo IzQuierdo, A.L., «La mediación familiar como complemento del proceso judicial de familia», Revista de Derecho de Familia 26, Valladolid, 2005, p. 292.

${ }^{60}$ Así, CAMPO IZQUIERDO, A.L., «La mediación familiar como complemento del proceso judicial de familia», cit., p. $29^{2}$.

${ }^{61}$ Como apunta SARIEgo Morillo, J.L., «Mediación intrajudicial o mediación extrajudicial», cit., p. 37I. 
suficientes para llevar a cabo la mediación, mediante las prácticas o la rotación entre los miembros del equipo.

\subsection{Código deontológico}

Como en el resto de los campos profesionales, la mediación está presidida por una serie de fundamentos éticos y deontológicos que rigen, informan e inspiran la intervención y la función mediadora. En nuestro país, la práctica de la mediación es temprana y, por ello, todavía se está constituyendo y formando esta deontología profesional. Como cualquier código ético profesional, éste debería recoger no sólo los principios éticos sobre los que se basa el desarrollo de la profesión, sino también los límites en su ejercicio, la responsabilidad por la mala práctica de los mediadores y organismos de mediación, los derechos de las partes, etc.

Ante la ausencia de este código, la única aproximación a una deontología que complete el estatuto del mediador se encuentra de nuevo en las leyes autonómicas que, en materia de derechos del mediador, coinciden, prácticamente, en señalar la existencia de los siguientes:

$\left.\mathrm{I}^{\circ}\right)$ El derecho a poner fin de al proceso de mediación, cuando no hay colaboración de las partes o es evidente la imposibilidad de mediar o lograr acuerdos, totales o parciales.

$2^{\circ}$ ) El derecho a poder renunciar a iniciar la mediación.

$\left.3^{\circ}\right)$ El derecho a cobrar los honorarios pertinentes.

Mientras la Ley de mediación familiar catalana no formula los derechos del mediador sistemáticamente, y éstos se hallan diluidos en diversos capítulos, la Ley de Castilla y León, contiene el catalogo más completo y sistematizado de derechos y deberes del mediador, no superado por ninguna de las publicadas posteriormente.

Como colofón al estatuto que estamos viendo del mediador, y en referencia a las aptitudes que a éste le deben ser exigidas, consideramos que la mejor definición de los caracteres de esta figura es la que realizaron del Secretario de Estado norteamericano H. Kissinger sus colaboradores más inmediatos. De él subrayaban «su paciencia y su capacidad para ver un problema desde una vasta perspectiva estratégica y luego traducirla en un comportamiento práctico, operativo y táctico, acompañado de una cálida comunicatividad, su sentido del humor y de la oportunidad ${ }^{62}$.

Es, quizá, ésta la mejor definición de lo que debiera constituir un mediador familiar. No obstante, para todos aquellos casos en que una persona no cuente naturalmente con estas aptitudes, será preciso que se asegure su competencia e idoneidad, con la formación adecuada para adquirirlas, a través, incluso, de la reglamentación del ejercicio de esas aptitudes como disciplina profesional.

\footnotetext{
${ }^{62}$ Cfr. TouzARD, H., Mediación y la solución de los conflictos: estudio psicológico, cit., p. I45.
} 


\section{Conclusión}

Todo lo anteriormente expuesto completa una aproximación al recurso a la mediación familiar que para los procesos de separación y divorcio se prevé en la LEC de 2005, a partir de la reforma operada por la Ley 15/2005, de 8 de julio. La mediación familiar, denominada «intraprocesal», no busca evitar el proceso jurisdiccional, sino que pretende que desaparezca su carácter «adversarial» y que el proceso se beneficie de sus virtudes.

La reforma ha previsto la utilización de esta técnica, tanto para conseguir un convenio regulador consensuado e iniciar un proceso matrimonial de mutuo acuerdo, como para la reconversión en éste de un proceso matrimonial contencioso, tras la solicitud al Juez de su suspensión. Otros trámites procedimentales en que puede recurrirse a la mediación, como son los existentes para la adopción de medidas provisionales, la modificación de medidas definitivas y la ejecución de sentencia, si bien no se mencionan expresamente, pueden inferirse de la regulación general de la LEC.

Y ante las dudas que pueden suscitarse en ausencia de una reglamentación general de la mediación familiar, habrá que acudir a la regulación de los procesos matrimoniales y a la legislación de mediación familiar de carácter autonómico. Así, sin suponer merma alguna del principio de voluntariedad - el inicio, el desarrollo y la finalización del procedimiento de mediación debe descansar, en todo caso, en la decisión de ambas partes-, queda claro que la iniciativa para comenzar el procedimiento de mediación debe reconocerse tanto a las partes como a la autoridad judicial.

Por el contrario, menos certeza presenta el carácter público o privado que deba revestir la mediación, puesto que, presentando ambas indudable ventajas, dependerá de quien se encuentre al frente del procedimiento. En este sentido, el estatuto del mediador familiar constituye una de las grandes incógnitas que presenta esta ausencia de regulación. Por la especial consideración de los problemas a tratar, es indudable, según creemos, que al frente de esta figura debe estar siempre un profesional del Derecho, con experiencia en la resolución de conflictos familiares, y debidamente formado en las técnicas de mediación.

Al igual que no debe dejarse que sea la práctica, a veces subterránea y obscura, la que se encargue de cubrir las lagunas que plantea el procedimiento. Es importante que, a través de su reglamentación, se produzca la divulgación de este recurso entre los profesionales del foro, facilitando al Juzgador y a los Abogados la posibilidad de utilizarla y buscando con ello que no se devalúe y se convierta en un instrumento pasivo y privado de cualquiera de sus fines, como ha ocurrido con la mediación obligatoria en el ámbito laboral.

Sin olvidar que, en aras del principio de igualdad, todos los ciudadanos españoles, con independencia de la Comunidad Autónoma a la que pertenezcan, han de tener las mismas posibilidades de acudir a la mediación cuando se vean inmersos en un conflicto que desemboque en un proceso de divorcio o separación matrimonial, resulta absolutamente necesaria, en cumplimiento de lo previsto en la Disposición Final $3^{\text {a }}$ de la Ley $15 / 2005$, de 8 de julio, la pronta regulación, a través de una Ley nacional, de la mediación familiar. 